Article

\title{
A Gender-Focused Prism on the Long-Term Impact of Teachers' Emotional Mistreatment on Resilience: Do Men and Women Differ in Their Quest for Social-Emotional Resources in a Masculine Society?
}

\author{
Niva Dolev *, Yariv Itzkovich (D) and Bat Katzman (D) \\ School of Humanities, Kinneret Academic College on the Sea of Galilee, Tzemach 15132, Israel; \\ itzkovichyariv@mx.kinneret.ac.il (Y.I.); Katzman2@gmail.com (B.K.) \\ * Correspondence: nivadolev@kinneret.ac.il
}

check for

updates

Citation: Dolev, N.; Itzkovich, Y.; Katzman, B. A Gender-Focused Prism on the Long-Term Impact of Teachers' Emotional Mistreatment on

Resilience: Do Men and Women

Differ in Their Quest for Social-Emotional Resources in a

Masculine Society? Sustainability 2021,

13, 9832. https://doi.org/

10.3390/su13179832

Academic Editor: Adar Ben-Eliyahu

Received: 19 June 2021

Accepted: 27 August 2021

Published: 1 September 2021

Publisher's Note: MDPI stays neutral with regard to jurisdictional claims in published maps and institutional affiliations.

Copyright: (c) 2021 by the authors. Licensee MDPI, Basel, Switzerland. This article is an open access article distributed under the terms and conditions of the Creative Commons Attribution (CC BY) license (https:/ / creativecommons.org/licenses/by/ $4.0 /)$.

\begin{abstract}
As a personal resource, resilience enables individuals to cope with stressful life events and to adapt to diverse situations. In the framework of Conservation of Resource (COR) theory, the current study investigates whether personal and social resources, namely emotional intelligence (EI) and gender, can contribute to resilience for individuals who experienced teacher mistreatment as adolescents. Our findings show that men and women differ in their baselines concerning mistreatment and emotional intelligence. Individual resources in the form of EI and social resources, and particularly gender, affect resilience. Moreover, gender and the Use of Emotion (UOE) facet of EI interact in their contribution to resilience. These findings provide better insights into the interrelationships between the diverse resources affected by past teacher mistreatment. An enhanced understanding can help us mitigate teacher mistreatment and promote more socially sustainable communities that are just and equitable, and support the emotional and social growth and resilience of its members
\end{abstract}

Keywords: resilience; conservation of resource theory; emotional intelligence; gender; teacher mistreatment; sustainability

\section{Introduction}

Resilience is defined as the ability to maintain or regain mental health in the face of adversity [1]. Scholars refer to resilience as a resource that enhances adaptability and the ability to cope with stressful life events [2,3], or as a restorative mechanism that enables individuals to recover or even grow from adverse conditions [4]. Resilience nourishes the interactions between individual attributes and the surrounding environment, including, but not limited to, situational experiences that play a role in shaping one's resilience [5]. Schools, and, more specifically, relations with teachers, provide a central situational experience that can shape individuals' resilience [2,6].

Although some recent literature has noted that young adults mistreated by teachers have lower levels of resilience than their counterparts who were not subject to such mistreatment [7-9], research has largely overlooked the long-term negative impact of teachers' mistreatment on students' resilience [2]. This lacuna in the scholarship stands in stark contrast to the thoroughly researched understanding that positive teacher-student relationships play an important role in children's development and learning [6,10].

In parallel, cultivating emotional intelligence (EI) - the ability to identify, use, understand and regulate emotions [11] — has been found to be crucial for shaping ones' resilience [12]. However, being a perishable resource, EI can decrease once mistreatment is experienced and can be then less available as a resource for future coping [13]. Yet the interrelations between EI and resilience in the framework of long-term impact of mistreatment by teachers has also been overlooked. Finally, the interplay between context (i.e., quality 
of relations with teachers as expressed by mistreatment) and personal resources (namely EI) as an antecedent of resilience is shaped by broader social and cultural forces, such as gender and its prominence in diverse cultural contexts.

Gender is considered a prominent feature that influences how individuals experience and manage stressful life events [14]. Some research has more specifically shown men to be more resilient than women $[15,16]$. At the same time, boys have been found more likely to be exposed to teacher mistreatment than girls [17], which, in turn, may reduce their resilience. These gender differences in resilience may reflect differences in the types of social-ecological stressors that men and women face and anticipate (such as mistreatment), differences in support and personal resources they have and expect to have (such as EI), and disparities in the power to negotiate and influence their contexts [15].

The role of gender in the framework of mistreatment should be further examined, especially as a factor that contributes to the development of resilience throughout life and, thus, as an antecedent of social sustainability of individuals and communities. Moreover, gender is not an absolute variable, but is highly dependent on its cultural attribution [18,19]. In masculine societies, gender is a resource of power, status, and prestige for men, while it may be a barrier and a source of relative deprivation for women [20]. Taken together, gender, EI, and resilience are all resources that individuals seek to restore, maintain, and increase continuously, the latter two being coping resources strongly affected by gender, and a social resource dependent on context [21].

Applying the Conservation of Resource (COR) theory [21] enables us to better understand the interrelations between stress arising from teacher mistreatment, personal resources (i.e., EI and resilience), and social resources (i.e., gender in its cultural context), all of which interact in complex ways as part of a multi-layered process aimed at restoring, maintaining, and increasing resources. When COR theory is applied as a theoretical framework, it introduces a dynamic model of stress that elucidates how individuals' resources function in the process of reducing their exposure to stressors, such as mistreatment by teachers. In this respect, gender, EI, and resilience are all resources that interact and nourish each other. Although gender is not a variable resource from a biological perspective, socially, it interacts with other resources, and the way in which it is viewed by the self and others can be shaped and altered. Studies have consistently shown that individual psychological differences (also triggered by gender) lead to the adoption of different coping strategies and other emotional and regulatory resources in the face of difficult situations [22].

COR theory, based on four underlying principles, helps clarify the drivers and underlying processes of exposure to mistreatment, while considering the dynamic nature of stress and its underlying processes. First, COR theory recognizes that people are motivated by resource loss more than by resource gain. Second, it postulates that people must invest resources to protect against future resource loss, to recover from loss, or to gain resources. Third, it emphasizes that resource gain is more prominent in the context of resource loss. Fourth, it posits that when resources are overstretched or exhausted, individuals enter a defensive mode to preserve the self. Moreover, over time, loss of resources affects the level of available resources that could be used in future stressful events, thus illustrating both the dynamic nature of processes and their predictive power [23].

These individual resources enable individuals to cope with adverse life events and stressful situations [24,25]. In the framework of teacher mistreatment, gender and EI are considered resources that can help, or prevent, individuals from acquiring additional resources. Thus, the overarching aim of the current study was to examine the multi-layered impact of past teacher mistreatment on social-emotional resources, namely EI and resilience, using the COR theory and accounting for gender in its cultural context. Specifically, we examined whether past mistreatment by teachers, as recalled by young Arab Israeli adults, who live in a society culturally characterized as masculine [26], had an impact on their current EI resources and resilience and, if so, whether the impact is different for women and men. Such a comparison has not yet been made, although the understanding of the 
long-term impact of the quality of relations with teachers in the past can help us enhance individual resilience using a more appropriate, gender-sensitive approach, which, in turn, can contribute to socially sustainable communities in which men and women are equally treated and their EI and resilience can be built.

\section{Literature Review}

\subsection{Resilience}

Resilience can be conceptualized in three different yet overlapping ways [27]: first, as a personal resource that helps individuals overcome disadvantaged circumstances and maintain and regain mental health in the face of adversity [1]; second, as the competence to cope with stress and threats to well-being [2,3]; and finally, as a positive functioning indicating recovery from traumatic experience [28]. Common to these different definitions is the fact that resilience occurs in the face of adversity [27] and that it influences the ability to successfully adapt to adverse circumstances [5].

Resilience can be further viewed as both a process in which personal attributes, environmental factors, and situational experiences interact, and as the outcome of this process [28]. As a process, resilience is dynamic and changing [29] and depends on one's interactions and surrounding environment $[27,29,30]$. Mistreatment can be one element of the surrounding environment. As an outcome, the building blocks of resilience include qualities such as optimism and interpersonal relationships [12], which are also part of the concept of EI. It has further been noted that adverse experiences can damage one's resilience and EI, and thereby become a source of vulnerability and hinder an individual's ability to cope with stressors in the long term $[4,27,29,30]$. Therefore, it is important to understand and address the underlying mechanisms that either inhibit or enhance resilience.

A substantial body of literature has examined the determinants of resilience among mistreated children [31], observing deficits in resilience when they became young adults relative to non-mistreated counterparts [7,9]. Yet, as noted above, the links between past teacher mistreatment and student resilience have largely been overlooked [32], despite the prevalence and potential impact of teachers' mistreatment [33].

\subsection{Teacher Mistreatment}

Teacher mistreatment is defined as a pattern of verbal and non-verbal behaviours of teachers towards students that does not include physical contact [2]. Mistreatment in a school context includes one or more of the following teacher behaviours: yelling, name-calling, insulting or denigrating (verbal abuse), or ignoring or punishing students (non-verbal abuse) [2,34]. This behaviour is targeted at a student or group of students [35]. This abusive experience, which can be a one-time or recurring event with different frequencies [34-36], is a widespread problem in many countries [2,33,37-39].

The impact of mistreatment on individual resources is unquestionable. Although positive teacher-student relationships act as a defence shield, helping students gain and maintain resources and thereby contributing to their resilience [40], abusive behaviours towards students are one of the most significant sources of school stress for students [41], resulting in a potential loss of resources [23]. Such resource loss is accompanied by psychological, social, cognitive, and somatic consequences for the student's functioning and adjustment [2,29,38], including long-term negative consequences for social-emotional resources in the years following the school experience [38,42].

Based on these findings we postulate the following: H1-Past experience of teacher mistreatment will decrease targets' resilience.

\subsection{Emotional Intelligence (EI)}

Resilience includes a series of individual attributes that can facilitate the ability to cope with stressful life events. These personal resources, both intra-personal (cognitive appraisals, positive affect and tolerance of negative affect, impulse control, optimism, stress tolerance, flexibility, and sense of competence) and interpersonal (secure relationships, 
directedness towards others, and the ability to engage in the support of others [12,29]) are typically included in the concept of EI [43], noting the links between the two concepts. Drawing on the social-ecological systems approach of development [44] and connecting it to teachers [45], it was suggested that the classroom climate, of which mistreatment is a part, is shaped by many different layers, including intrapersonal and interpersonal factors, in addition to culture and educational policies.

Essentially, EI refers to the effective integration of emotion and cognition, and involves the ability to identify and express emotions, to understand emotions and emotional knowledge in the self and in others, to assimilate emotions in thoughts and use them in thought processes, and to regulate both positive and negative emotions in the self and in others [11]. Some researchers have used a broader perspective, looking at social-emotional skills and competencies that underlie EI, and have noted that EI enables individuals to cope with daily life and adversity [43] and stress [44]. Similarly, EI has been found to be linked to psychological health [45], subjective well-being [43], and positive attitudes [46]. It has been explained that emotions play a fundamental role in shaping reactions to external stimuli. The ability to identify, use, understand, and regulate emotions therefore helps construe situations as challenging rather than as threatening, employ a more positive and less negative affect, alter emotions to redirect cognitive processes, obtain new perspectives and solve problems, and react in personally effective ways $[47,48]$.

Studies have further shown that EI can protect against the likelihood of abusive experiences actually occurring [49-51] and can help one cope with mistreatment-related stress [44]. Thus, EI can help students better conserve their resources when faced with mistreatment. However, EI appears to be a perishable resource that can be depleted by adverse experiences, such as mistreatment, and several studies have noted a direct impact of mistreatment on the ability to use EI skills among adults [52,53], including in educational settings [54]. Less is known about the impact of teacher mistreatment on the EI resources of victimized children, but one study showed teacher mistreatment to be negatively correlated with EI later in life [42]. Therefore, we postulate: H2-Past experience of teacher mistreatment will decrease targets' EI.

Studies have also more directly connected EI and resilience, with the vast majority of such studies showing that people with better EI have better resilience, particularly resilience to stress [48]. Based on these studies, we posed the following hypothesis: H3-EI competencies will enhance resilience.

Stress, which is a product of mistreatment, was found to be adversely related to resilience and EI [12]. As EI is both an antecedent of resilience [48] and a consumed resource of mistreatment $[53,54]$, we can postulate that EI will mediate the interrelations between mistreatment and resilience: $\mathrm{H} 4-\mathrm{EI}$ will mediate the relations between teacher mistreatment and resilience.

These interrelations are embedded and nourished from the social context, namely gender and its cultural context.

\subsection{Resilience and EI: A Sociocultural Lens}

Gender plays a key role in teacher-student relationships [55,56] as manifested in teachers' expectations, attributions of failure and success [57-59], and diverse attitudes and behaviours towards male and female students. These gender-based diversities and biases are expressed through differences in time allocated for questions for boys and girls, type of answers, praise, and condemnations $[17,60]$. More specifically, although considerably more research is needed [2], existing evidence has consistently shown that male students are more likely than females to report emotional victimization by teachers $[2,39,61,62]$. These findings can be explained by differences in teachers' interpretations of students' behaviours and discipline problems that impact students' responses, including mistreatment responses. When teachers interpret students' discipline problems as reflecting their own failures to manage behaviour in the classroom, which is more likely to happen with boys than with girls [63], their response can be inappropriate and even aggressive [64]. These perceptions 
interact with students' prior gender expectations and related behaviours acquired from families and society at large that construct social hierarchies based on gender [55]. Thus, we predict that men will report significantly higher levels of past mistreatment by teachers than will women: H5-Men will report higher levels of past teacher mistreatment than women.

In turn, these social hierarchies have an impact on an individual's ability to control impulses, to become engaged in relationships, and to find support, all of which are components of EI. Data regarding gender-related EI differences is inconclusive, but many studies suggest gender-related EI differences, showing mainly a female advantage $[60,65,66]$. Others have found that males scored lower than females on the four main EI abilities: perceiving, using, understanding, and regulating emotions [67]. Others have not found such differences [43,68-71] but have noted gender-related differences in some EI competencies. Women were often found to demonstrate higher emotional self-awareness, in particular, emotional perception [72], emotional expression [73], and emotion recognition, especially involving less intense emotions [67], in addition to interpersonal skills, such as empathy and managing relationships [66,74]. Males, in contrast, were found in some studies to score higher on skills such as impulse control and stress management [66].

Differences in EI were attributed, at least in part, to socialization processes and expectations, in addition to early child-parent interactions [75]. In these socialization processes, often shaped by sociocultural factors, females are encouraged to be cooperative, expressive, and attuned to their interpersonal world, whereas males are instructed to be openly competitive, independent, and instrumental [66]. In light of this extensive data, we postulate that women's EI will be higher than that of men: H6-Women will have higher EI compared to men.

These gender differences are also considered to influence resilience-how individuals manage stressful life events. Studies have shown males to be more resilient than females $[15,16]$, suggesting greater protective resources when facing teacher mistreatment. These gender differences may reflect variations in the types of social-ecological stressors that men and women face and anticipate, differences in the support and resources they have and expect, and disparities in the power to negotiate and influence their contexts [15].

These socializations are rooted in and correspond with cultural attributes that ultimately are considered to be "the collective programming of the mind that distinguishes the members of one group or category of people from others" - of which one example is gender [19] (p. 3). Masculine cultures emphasize emotional and social role differentiation between the genders, highlight success, achievements, and competitiveness [76], and expect men to be strong, assertive, and ambitious, whereas women are expected to be feeling-focused, non-aggressive, modest, and caring [18]. Thus, in masculine societies, expectations for males and females are aligned with and shaped by what is valued in society [19]. Larger gender differences in seeking social support and discussing emotional difficulties can be expected among members of the masculine Arab culture [26]. Specifically, in these societies, gender is a social resource for men that fosters resilience, but, at the same time, leads to mistreatment by teachers [2], that, in turn, reduces resilience. These two contradicting influences may neutralize each other. Thus, we postulate that: H7-Gender will have an impact on resilience; men, in particular those from masculine societies, will be more resilient than women; and: H8-Men and women will report similar levels of resilience.

EI and gender are considered as resources in the framework of COR. Drawing on the third principle of COR, postulating that resource gain is more prominent in the context of resource loss [23], we predict that high levels of EI are more salient in the contexts of gender inferiority. Similarly, under low EI conditions, gender will prove a more meaningful factor for men, as it will be evaluated in the context of EI absence. Thus, we also postulate that: H9-EI competencies and gender interact in such a way that EI will enhance resilience more for women. 
The overarching goal of the current study was to account for the long-term impact of context (past teacher mistreatment) on individual and social resources of young adults and their interrelations. Specifically, the following research hypotheses were therefore formulated:

H1-Past experience of teacher mistreatment will decrease targets' resilience.

H2-Past experience of teacher mistreatment will decrease targets' EI.

H3-EI competencies will enhance resilience.

$\mathrm{H} 4-$ EI will mediate the relations between teacher mistreatment and resilience.

H5-Men will report higher levels of past teacher mistreatment than will women.

H6-Women will have higher EI compared to men.

H7-Gender will have an impact on resilience. Men, in particular those from masculine societies, will be more resilient than women.

H8-Men and women will report similar levels of resilience.

H9-EI competencies and gender interact in such a way that EI will enhance resilience more for women than for men.

\section{Materials and Methods}

\subsection{Participants}

The sample consisted of 201 Arabs adults who live in urban and/or rural areas in Northern Israel. Of the sample, 97 were men and 104 were women. The mean age for men was $27.7(\mathrm{SD}=7.9)$, and for women, $25.6(\mathrm{SD}=6.9)$. Slightly over $80 \%$ of the men and women reported their economic status as good or very good. Respondents were assured anonymity and were encouraged to respond truthfully. They were permitted to withdraw from the study at any time and for any reason.

\subsection{Data Analysis}

Data were analysed using SmartPLS3 [77] and SPSS version 25. Specifically, SPSS was used to examine gender differences concerning the experience of emotional abuse in the past, and to test gender differences concerning current levels of EI and resilience. SmartPLS3 was used for testing the measurement model and the structural model. SmartPLS3 is especially suitable for studies with samples that are not very large [77].

\subsection{Instrumentation}

Generally, the EI components were measured as reflective scales, whereas the past experiences of school violence and resilience were measured as formative scales according to established guidelines. Depending on the direction of the relationship between the construct and its indicators, scholars have recognized two main measurement models, formative and reflective, depending on whether the direction of the relationship is from the construct to the measures (i.e., reflective measurement) or from the measures to the construct (i.e., formative measurement).

Reflective measurement models emphasize the construct as the cause of measures; consequently, a variation in the construct leads to a variation in its measures. It is termed reflective because it indicates reflections, or manifestations, of a particular construct. Because reflective indicators reflect the same underlying construct, they should all have the same antecedents and consequences, and should be conceptually interchangeable. Alternatively, formative indicators represent different dimensions of a particular construct, meaning that the composite construct is derived from its measures. A formative construct, mostly in the form of rankings or an index, presents an aggregate of the observed variables with which it is associated and emphasizes the role of indicators as predictors rather than predicted variables; that is, the phenomenon is defined by or is a function of the observed variables [77].

Whereas evaluation using a formative measurement scale requires assessment of collinearity and the relevance of indicators' contributions (outer weights), the assessment of reflective scales requires convergent validity and reliability tests and the assessment of 
outer loading. Additionally, in formative measures, reliability tests are not required as part of the measurement assessment, because the items (questions) composing the formative measurement scale represent different dimensions of the construct and are not necessarily intercorrelated.

Results of the measurement models indicated that there were no collinearity or loading issues for the formative measures. Furthermore, as reflected in Table 1, SmartPLS3 analysis showed that all reflective variables were reliable.

Table 1. Result summary for the measurement models.

\begin{tabular}{lcc}
\hline Latent Variable & $\begin{array}{c}\text { Convergent } \\
\text { Validity }\end{array}$ & $\begin{array}{c}\text { Internal Constituency } \\
\text { Reliability }\end{array}$ \\
\hline & Cronbach's Alpha & AVE \\
OEA & $>0.70$ & $>0.50$ \\
ROE & 0.772 & 0.593 \\
Resillience & 0.876 & 0.729 \\
SEA & Formative & Formative \\
Past experience of school violence & 0.847 & 0.688 \\
UOE & Formative & Formative \\
\hline
\end{tabular}

Specifically, emotional abuse by teachers was measured through a nine-item selfreport Emotional Abuse Scale (EAS) to assess the frequency of various types of emotional abuse suffered at the hands of the teacher within a school context. This scale was developed by Nearchou (2018) and was based on the revised Psychological Maltreatment Subscale (PMS) by Whitted and Dupper (2008) [2,38]. The items of EAS include verbal and nonverbal behaviours that are generally perceived as acts of emotional abuse or neglect by teachers based on the literature review. Confirmatory Factor Analysis (CFA) was applied to test whether the scale structure fit the data, and the results showed a good fit [2]. The scale was translated from English to Hebrew using the translation-back translation procedure [78]. All items were rated on a 4 point Likert scale $(0=$ Never happened, to 3 = Happened four times or more). Participants were asked to indicate if and how often they experienced specified behaviours by their teacher when they were students at school, such as: "Your teacher said bad things about your family." The answers were then re-coded to $0=$ Never happened and 1 = Happened at least once.

Emotional intelligence was measured through the 16-item Wong and Law Emotional Intelligence Scale (WLEIS) [79] based on the Salovey-Mayer EI framework [11], which covers four EI dimensions: Self-Emotion Appraisal (SEA); Others' Emotion Appraisal (OEA); Use of Emotions (UOE); and Regulation of Emotions (ROE), each comprising four items. Participants were asked to indicate the extent to which they agreed with each statement on the associated EI questionnaires using a 5 point Likert scale ranging from strongly disagree (1) to strongly agree (5). A sample statement was: "I really understand what I feel".

Resilience was measured through the Child and Youth Resilience Measure (CYRM-12), a 12-item, self-report measure assessing the current resilience of the participant developed by Liebenberg, Unger, and Leblanc (2013) [80]. The scale was translated from English to Hebrew by using the translation-back translation procedure [78]. All items were rated on a 5 point Likert scale $(0=$ Not True about me to $5=$ Very true about me). Participants were asked to indicate to the extent to which the subsequent sentences correctly described how they currently feel. For example, "I am trying to finish what I am starting" and "I know how to get help and support when I need it".

\subsection{Procedure}

Questionnaires were distributed online to students at one college in northern Israel. Using a snowball approach, the students were asked to invite family members, friends, and acquaintances to participate in the study. In addition, the link was distributed via 
WhatsApp groups and Facebook. The sample was limited to those at least 18 years old. Participants were informed that their responses would remain anonymous, and that participation was voluntary. Participants were not compensated for their involvement. In line with ethical standards, the study was approved by the Ethical Review Board of the college.

\section{Results}

To determine whether participants' emotional abuse differed across gender, a binomial test was applied [81]. The pattern was consistent. Men reported experiencing every item on the emotional abuse by teachers scale more frequently than did women $(p<0.002)$.

Additionally, an independent sample t-test analysis was conducted to test for differences between men and women in their EI levels and their resilience. The test showed that, on average, women $(\mathrm{M}=4.08, \mathrm{SD}=0.62)$ had significantly higher EI than men in all subscales $(\mathrm{M}=3.85, \mathrm{SD}=0.70 ; \mathrm{t}(199)=-2.53, p<0.05)$. However, no significant differences were found between men and women in their resilience $[\mathrm{t}(199)=-1.39, p>0.05)]$.

To assess the research hypotheses, a research model was constructed in SmartPLS3. As shown in Figure 1, based on the theoretical model, connections were specified between gender, past experienced school mistreatment, four EI dimensions, and resilience. Additionally, the moderating effect of gender on the relationship between UOE and resilience was tested. Our research model also accounted for the mediation effect of EI on the relationship between past experienced school mistreatment and resilience.

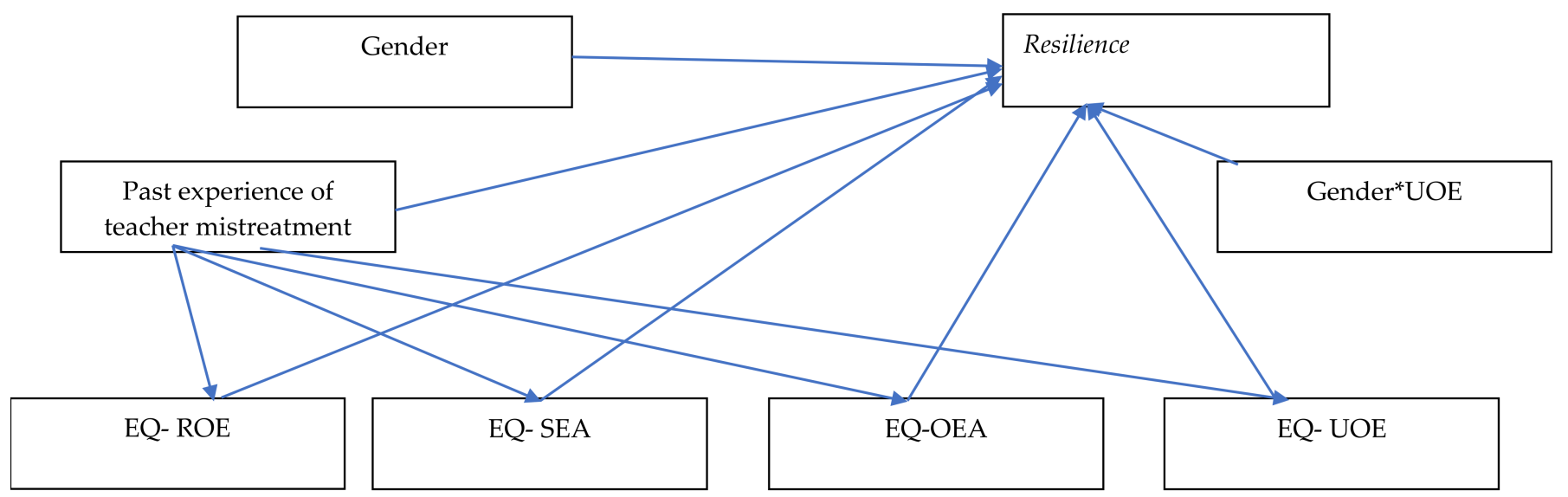

Figure 1. The theoretical structure of the proposed framework.

The PLS algorithm is an assessment process embedded in SmartPLS3 that allows the assessment of the measurement model as described in Figure 1. The assessment is based on bootstrapping, a nonparametric procedure that allows for testing the statistical significance of various PLS-SEM results, such as path coefficients, Cronbach's alpha, HTMT, and $R^{2}$ values. The transition between CB-SEM, which is based on model fit, and PLS-SEM, which is based on prediction, requires a change in the structure of the research.

Results of the PLS algorithm showed that the $R^{2}$ result for resilience was moderate (0.55), whereas the $R^{2}$ value of each of the EI dimensions was rather weak and ranged from 3 to $7 \%$, with the exception of the UOE subscale (0.13). In addition to measuring the $R^{2}$ values, the change in the $R^{2}$ value when a specified exogenous construct was omitted from the model was tested to evaluate its impact on the endogenous constructs. This measure is referred to as the $f^{2}$ effect size, where values of $0.02,0.15$, and 0.35 represent small, medium, and large effects, respectively [77].

Results also indicated weak effect sizes of past experienced teacher mistreatment on EI components. Specifically, past-experienced teacher mistreatment had weak effects on OEA (0.032), ROE (0.039), SEA (0.075), and UOE (0.149). In turn, these components had a 
weak effect size on resilience: SEA (0.089), UOE (0.216) and, finally, the interaction effect size was (0.035).

The blindfolding procedure was also used to assess the predictive relevance $\left(Q^{2}\right)$ of the path model. Values larger than 0 suggest that the model has predictive relevance for a specific endogenous construct [77]. The $Q^{2}$ values showed predictive relevance of all endogenous scales: OEA (0.013); ROE (0.026); Resilience (0.128); SEA (0.040); UOE (0.085). Significance analyses of the direct effects are specified in Table 2.

Table 2. Significance analysis of the direct effects.

\begin{tabular}{lccc}
\hline & Direct Effect & $t$ Value & $p$ Value \\
\hline SEA-Resilience & 0.295 & 2.877 & 0.004 \\
\hline $\begin{array}{l}\text { Past experience of teacher } \\
\text { mistreatment-OEA }\end{array}$ & -0.176 & 2.162 & 0.031 \\
\hline $\begin{array}{l}\text { Past experience of teacher } \\
\text { mistreatment-ROE }\end{array}$ & -0.194 & 2.546 & 0.011 \\
\hline $\begin{array}{l}\text { Past experience of teacher } \\
\text { mistreatment-SEA }\end{array}$ & -0.264 & 3.426 & 0.001 \\
\hline $\begin{array}{l}\text { Past experience of teacher } \\
\text { mistreatment-UOE }\end{array}$ & -0.360 & 4.698 & 0.000 \\
\hline UOE-Resilience & 0.455 & 3.677 & 0.000 \\
\hline UOE $\times$ Gender-Resilience & 0.138 & 1.981 & 0.048 \\
\hline
\end{tabular}

As can be seen in Table 2, past experiences of teacher mistreatment had a negative effect on all components of EI. Additionally, resilience was explained through SEA and UOE. It was also found that gender moderated the relationship between UOE and resilience. To assess the interaction, as presented in Figure 2, a simple slope analysis was conducted and revealed that high UOE contributed more to women's resilience than to that of men, whereas low UOE damaged women's resilience more than it did that of men.

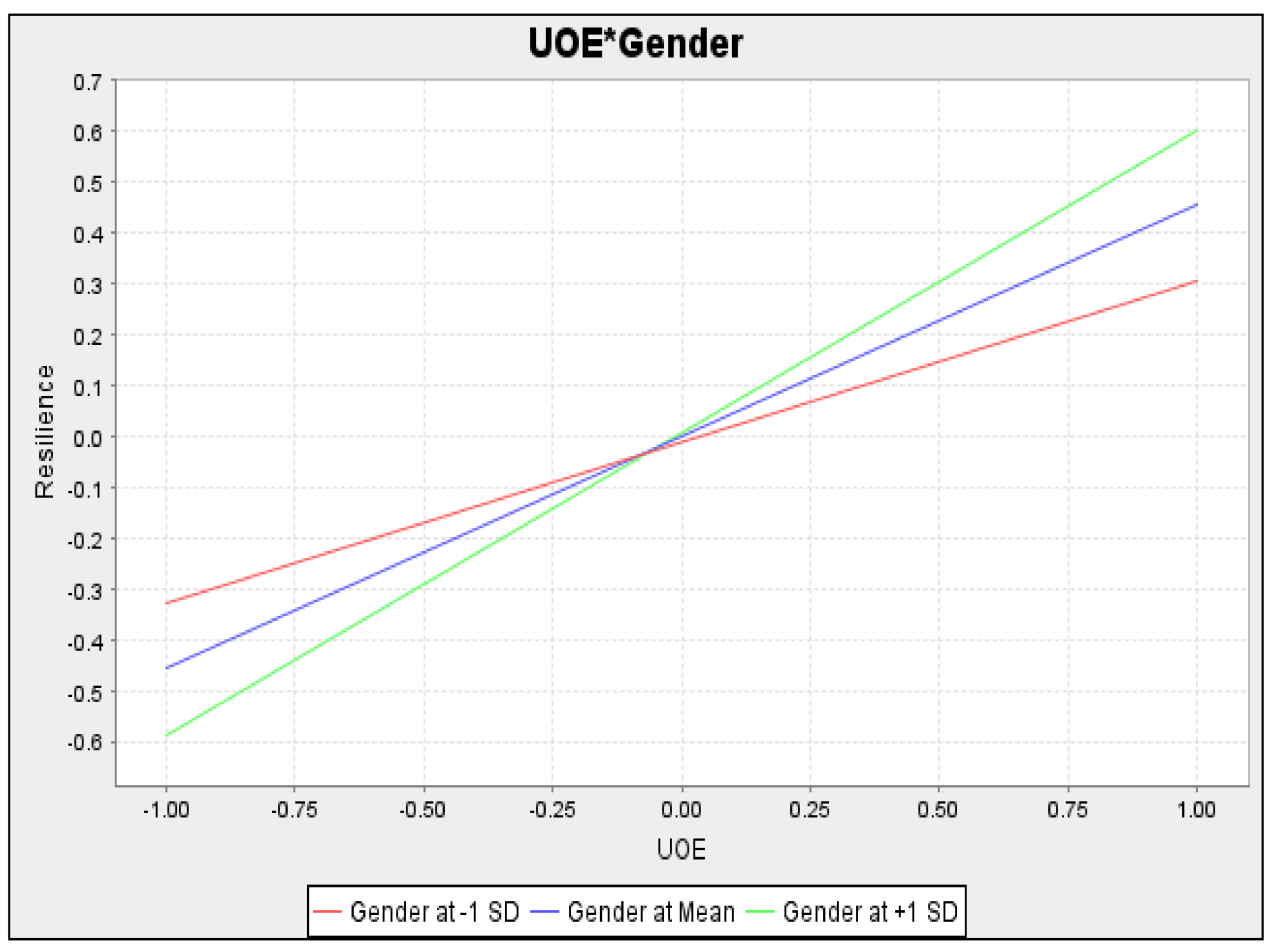

Figure 2. Simple slope analysis of the interaction effect. 
In addition to the results indicated in Table 2 and Figure 2, an indirect effect of the experience of teacher mistreatment on resilience, mediated via UOE, was found $(-0.36 \times 0.45=-0.16)$. The significance of this indirect effect was tested using the bootstrapping procedure, and the bootstrapped unstandardized indirect effect was statistically significant $(t=2.556, \mathrm{p}<0.001)$. Thus, past experience of teacher mistreatment on resilience was fully mediated via UOE.

\section{Discussion}

The current study addressed the long-term impact of context (teacher mistreatment) on individual (EI and resilience) and social (gender) resources of young adults and their interrelations in the framework of COR. In this context, it enabled us to understand the complex, diverse, and at times even opposing forces that construct individual resources. In doing so, the current study took a broader approach, accounting for individual and social attributes that shape one's resilience in the context of teacher mistreatment.

Our first two predictions focused on the long-term impact of teachers' mistreatment on resilience. Although deficits in resilience in mistreated young adults relative to nonmistreated counterparts have been observed [7,9], the interrelations between past teachers' mistreatment and students' resilience and their impact on EI have largely been overlooked [32], despite the prominence and potential impact [33] of teachers' mistreatment, including the long-term impact [37]. This finding reinforces the notion that teachers play a key role in cultivating individuals' socio-emotional competencies [82]. In this regard, schools and teachers should not only preserve students' resilience, but also act as safeguards, protecting students' individual resources that could be otherwise depleted over time due to life experiences [54] in all their interactions.

In turn, the existence of EI as a resource was positively correlated with resilience. This finding extends those of previous studies [48] to the context of teacher mistreatment and finds support in COR's second principle that postulates that people must invest resources to protect against future resource loss, recover from loss, or gain resources [23].

Additionally, it was found that EI mediates the relations between teachers' mistreatment and resilience. This finding is consistent with research showing the mediation of EI in the relationship between mistreatment at work and work outcomes and extending it to educational settings [54]. It can be explained that the ability to identify and understand negative emotions arising from mistreatment helps individuals use mechanisms for regulating and reconciling them.

Hypotheses H5-H9 considered gender as a socially constructed resource [26] and its ability to interact with the context (i.e., mistreatment), its impact in terms of individual resources, and its interaction with EI as a personal resource. As predicted, men reported higher levels of past teacher mistreatment than did women, a finding that is consistent with other research [56] that noted that gender plays a key role in teacher-student relationships. Our findings are also consistent with studies that more directly showed that males are more prone to teacher victimization compared to females [2,41,62].

In contrast, we found support for the differences between women and men concerning their EI levels. Our findings show that women possess higher levels of EI, a personal resource now favouring females. This finding corresponds with previous findings showing a female advantage in EI [65,66,83], or its main abilities: perceiving, using, understanding, and regulating emotions [67].

These differences were attributed to differences in early child-parent interactions [75] and to socialization processes in which females are encouraged to be attuned to their emotions and interpersonal world, processes that cultivate EI competencies. In particular, in Israeli Arab culture, women are raised to be domestic and act as the providers of emotional support to their families [26]. Males, in contrast, are encouraged to be openly competitive, independent, and instrumental [66], and to not share emotional distress or seek support, particularly in such a masculine society where they maintain their power and dominance [26]. In this respect, gender, as a resource, allows future enhancement of 
resources consistent with the COR second principle postulating that people must invest resources to protect against future resource loss, recover from loss, or gain resources [23].

As predicted, we did not find gender differences in resilience. This equality can be explained through the COR perspective that allows a deeper and more dynamic understanding of this finding. Studies have found males to be more resilient than females [15]. One explanation lies in gender inequality and the power that males hold serving as a resource [84]. In particular, Israeli-Arab women continue to accept their social status as lower than that of men [26]. Alternatively, other studies supported the notion that males, compared to females, are more likely to be victimized $[2,39,62]$, as they display behaviours that challenge teachers' class management. These two opposing sets of findings neutralize each other, so that gender contributes to men's resilience and EI contributes to women's resilience through masculine perceptions and attributions.

Our last and most interesting prediction was that EI competencies and gender interact in such a way that high EI will enhance resilience more for women, whereas its absence will result in gender contributing more to resilience of men than women. This finding can be explained by the third principle of COR postulating that resource gain is more prominent in the context of resource loss [23]. When the UOE element is high [85], it is significantly more meaningful for women who are considered inferior in terms of gender. In essence, UOE, which is the ability of a person to make the best use of emotions gearing them towards positive emotions and constructive activities, contributes more to women, because they lack the advantage of gender, especially in a masculine society [26]. Alternatively, when $\mathrm{UOE}$ is low, being a man is an advantage in terms of resources, a factor that is more salient in the context of low EI resources.

From a theoretical perspective, the utilization of COR allows us to account for the longterm impact of mistreatment and predict levels of resilience that were framed as resources. Additionally, accounting for gender in various forms of mistreatment has received scant attention in the literature. From a practical point of view, several implications for education systems arise from the findings and should be addressed, because teacher mistreatment hinders the essence of education and results in many negative outcomes for students. These implications concern the identification, intervention, and prevention of mistreatment, all of which facilitate the development of a comprehensive viewpoint of dealing with mistreatment [86].

In order to improve identification of teacher mistreatment, schools and teachers should become aware of the prevalence of mistreatment taking place, in particular as teaching is taking place behind closed doors, and efforts must therefore be made to create systems that identify mistreatment. As a starting point, schools should increase awareness of mistreatment and its implications, and train teachers to identify occurrences of mistreatment [87]. Although most teachers do not take an active part in students' victimizations, as bystanders they have a key role in identifying such occurrences [88].

From an intervention perspective, schools should invest in in-service training that develops acting teachers' social emotional skills that serve as a counterweight to mistreatment.

Teachers as potential bystanders should not only identify but also be able to support the targets of mistreatment [89-91]. This can be achieved through comprehensive EI training for teachers, who could then be able to create a supportive, caring, and respectful climate in their class, and develop resilience and social emotional skills in their students through modelling, daily interactions, and direct teaching.

From a student's perspective, students should be taught to how to act both as victims and as bystanders in cases of mistreatment. Social Emotional Learning (SEL) processes can enhance students' resilience and ability to cope with mistreatment cases that have not been identified by the system, thus minimizing both their occurrence and their negative impact. These efforts match with the more general recent aim of schools to develop resilience and social-emotional skills in students in order to equip them with skills required for coping and succeeding in the 21st century. More specifically, attention should be given to enhancing girls' UOE and resilience, given its specific impact on them, and to the cultural 
context in which the program takes place. Implementing school-wide resilience-building programs can teach important internal resilience and social-emotional skills to students and provide support to those who may have experienced mistreatment. These programs can be structured using a gender- and culture-sensitive view [92]. Such programs should begin by focusing on teachers' own resilience and should provide teachers with tools to develop resilience in their students to create a safe, emotionally intelligent, and resilience-building class and school climate.

A third pillar of the above-mentioned comprehensive approach for mitigating mistreatment is teachers who are entering education systems. In this respect, acceptance to education studies and recruiting new teachers to schools should include an evaluation of social-emotional skills that allow teachers to build a safe and empathetic class environment.

\section{Limitations}

Although this study has wide implications for teachers and education systems, a number of limitations can be identified. One limitation of the current study is its crosssectional design that does not allow us to determine causality. It might also be that EI can reduce mistreatment, rather than mistreatment damaging EI levels. This alternate viewpoint can be tested in future studies. The snowball sampling approach used may have attracted a certain type of people, such as individuals with more interpersonal contacts. Further studies may use more purposeful sampling and larger sample sizes to increase external validity.

Additionally, the current study measured all constructs, including past mistreatment experience, at a single point in time. A longitudinal perspective would help to further validate its results. Furthermore, because mistreatment is a multi-dimensional emotional experience, a mixed method study that incorporates qualitative interviews of mistreatment experiences, perceived impacts, and coping mechanisms could help shed light on the complex role of personal and situational factors.

Although some limitations were noted, the current study allows us a deeper understanding of the interrelations between social and individual resources when facing stress. Furthermore, it also allows us to design educational processes that will have positive impacts on students' personal and social resources, and help them construct affirmative and respectful relationships.

Overall, this study's findings can contribute to a sustainable society in which violence is denounced, EI and resilience are cultivated, and equality is promoted by cultivating UOE of women and, more generally, EI of all individuals to provide a good quality of life. Our findings also lead to a call for the promotion of feminine societies that believe in advancing human development, gender equity, and care for the weak [93] in order to shape sustainable societies.

Author Contributions: Conceptualization, N.D.; Data curation, B.K.; Formal analysis, Y.I. and B.K.; Investigation, Y.I.; Methodology, Y.I. and B.K.; Resources, N.D. and B.K.; Software, Y.I.; Supervision, N.D.; Writing - original draft, N.D., Y.I. and B.K.; Writing - review \& editing, N.D. and Y.I.; project administration, N.D. All authors have read and agreed to the published version of the manuscript.

Funding: This research received no external funding.

Institutional Review Board Statement: The study was conducted according to the guidelines of the Declaration of Helsinki and approved by the Institutional Review Board on 11 October 2020.

Informed Consent Statement: Informed consent was obtained from all subjects involved in the study.

Data Availability Statement: Data is available per request.

Conflicts of Interest: The authors declare no conflict of interest. 


\section{References}

1. Rutter, M. Resilience as a dynamic concept. Dev. Psychopathol. 2012, 24, 335-344. [CrossRef]

2. Nearchou, N. Resilience following emotional abuse by teachers: Insights from a cross-sectional study with Greek students. Child Abuse Negl. 2018, 78, 96-106. [CrossRef]

3. Luthar, S.S.; Cicchetti, D.; Becker, B. Research on resilience: Response to commentaries. Child Dev. 2000, 71, 573-575. [CrossRef]

4. Bezek, A. Gender Differences in Resilience in the Emerging Adulthood Population. Master's Thesis, Rochester Institute of Technology, Rochester, NY, USA, 2010. Available online: https:/ /scholarworks.rit.edu/cgi/viewcontent.cgi?article=10482\& context=theses (accessed on 30 August 2021).

5. Ong, A.D.; Bergeman, C.S.; Bisconti, T.L.; Wallace, K.A. Psychological resilience, positive emotions, and successful adaptation to stress in later life. J. Pers. Soc. Psychol. 2006, 91, 730. [CrossRef]

6. Roorda, D.L.; Koomen, H.M.; Spilt, J.L.; Oort, F.J. The influence of affective teacher-student relationships on students' school engagement and achievement: A meta-analytic approach. Rev. Educ. Res. 2011, 81, 493-529. [CrossRef]

7. Topitzes, J.; Mersky, J.P.; Dezen, K.A.; Reynolds, A.J. Adult resilience among maltreated children: A prospective investigation of main effect and mediating models. Child Youth Serv. Rev. 2013, 35, 937-949. [CrossRef]

8. DuMont, K.A.; Widom, C.S.; Czaja, S.J. Predictors of resilience in abused and neglected children grown-up: The role of individual and neighborhood characteristics. Child Abuse Negl. 2007, 31, 255-274. [CrossRef] [PubMed]

9. Mersky, J.P.; Topitzes, J. Comparing early adult outcomes of maltreated and non-maltreated children: A prospective longitudinal investigation. Child Youth Serv. Rev. 2010, 32, 1086-1096. [CrossRef]

10. Sabol, T.J.; Pianta, R.C. Recent trends in research on teacher-child relationships. Attach. Hum. Dev. 2012, 14, 213-231. [CrossRef]

11. Mayer, J.D.; Salovey, P. What is emotional intelligence? In Emotional Development and Emotional Intelligence: Educational Implication; Salovey, P., Sluyter, D., Eds.; Basic Books: New York, NY USA, 1997; pp. 3-31.

12. Sarrionandia, A.; Ramos-Díaz, E.; Fernández-Lasarte, O. Resilience as a mediator of emotional intelligence and perceived stress: A cross-country study. Front. Psychol. 2018, 9, 2653. [CrossRef]

13. Itzkovich, Y.; Dolev, N. Rudeness is not only a kids' problem: Incivility against preschool teachers and its impacts. Curr. Psychol. 2021, 40, 2002-2016. [CrossRef]

14. Barnett, R.C.; Biener, L.; Baruch, G.K. (Eds.) Gender and Stress; Free Press: New York, NY, USA, 1987.

15. Portnoy, G.A.; Relyea, M.R.; Decker, S.; Shamaskin-Garroway, A.; Driscoll, M.; Brandt, C.A.; Haskell, S.G. Understanding gender differences in resilience among veterans: Trauma history and social ecology. Trauma Stress 2018, 31, 845-855. [CrossRef]

16. Peng, L.; Zhang, J.; Li, M.; Li, P.; Zhang, Y.; Zuo, X.; Miao, Y.; Xu, Y. Negative life events and mental health of Chinese medical students: The effect of resilience, personality and social support. Psychiatry Res. 2012, 196, 138-141. [CrossRef]

17. Bayraktar, A. Possible effects of gender on teacher-student interactions. Procedia Soc. Behav. Sci. 2011, 15, 2545-2548. [CrossRef]

18. Hofstede, G. Geert Hofstede Cultural Dimensions. 2009. Available online: http://www.taylortraining.com/clients/mcc/ Hofstede_Cultural_Dimension_Explained(external).pdf (accessed on 30 August 2021).

19. Hofstede, G. Dimensionalizing cultures: The Hofstede model in context. Online Read. Psychol. Cult. 2011, 2, 2307-0919. [CrossRef]

20. Sheperd, M. Re-Thinking Masculinity: Discourses of Gender and Power in Two Workplaces. Ph.D. Thesis, University of Sheffield, Sheffield, UK, 1996. Available online: https:/ / etheses.whiterose.ac.uk/14914/1/480670.pdf (accessed on 30 August 2021).

21. Hobfoll, S.E.; Shirom, A. Conservation of resources theory: Implications to stress and management in the workplace. In The Handbook of Organizational Behavior, 2nd ed.; Golembiewski, R.T., Ed.; CRC Press: Boca Raton, FL, USA, 2000 ; pp. 57-81.

22. Freire, C.; Ferradás, M.D.M.; Valle, A.; Núñez, J.; Vallejo, G. Profiles of psychological well-being and coping strategies among university students. Front. Psychol. 2016, 7, 1554. [CrossRef]

23. Hobfoll, S.E.; Halbesleben, J.; Neveu, J.P.; Westman, M. Conservation of resources in the organizational context: The reality of resources and their consequences. Annu. Rev. Organ. Psychol. Organ. Behav. 2018, 5, 103-128. [CrossRef]

24. Ben-Sira, Z. Zionism at the Close of the Twentieth Century: A Dilemma; Edwin Mellen Press: Lewiston, NY, USA, 1993.

25. Goldner, L.; Lev-Wiesel, R.; Schanan, Y. Caring about tomorrow: The role of potency, socio-economic status and gender in Israeli adolescents' academic future orientation. Child Indic. Res. 2019, 12, 1333-1349. [CrossRef]

26. Pines, A.M.; Zaidman, N. Gender, culture, and social support: A male-female, Israeli Jewish-Arab comparison. Sex Roles 2003, 49, 571-586. [CrossRef]

27. Ungar, M. Resilience across cultures. Br. J. Soc. Work 2008, 38, 218-235. [CrossRef]

28. Litz, B.T. Resilience in the aftermath of war trauma: A critical review and commentary. Interface Focus 2014, 4, 20140008. [CrossRef]

29. Fritz, J.; de Graaff, A.M.; Caisley, H.; Van Harmelen, A.L.; Wilkinson, P.O. A systematic review of amenable resilience factors that moderate and/or mediate the relationship between childhood adversity and mental health in young people. Front. Psychiatry 2018, 9, 230. [CrossRef]

30. Ungar, M. The social ecology of resilience: Addressing contextual and cultural ambiguity of a nascent construct. Am. J. Orthopsychiatry 2011, 81, 1. [CrossRef]

31. Daigneault, I.; Dion, J.; Hébert, M.; McDuff, P.; Collin-Vézina, D. Psychometric properties of the Child and Youth Resilience Measure (CYRM-28) among samples of French-Canadian youth. Child Abuse Negl. 2013, 37, 160-171. [CrossRef]

32. Jackson, V.; Browne, K.; Joseph, S. The prevalence of childhood victimization experienced outside of the family: Findings from an English prevalence study. Child Abuse Negl. 2016, 51, 343-357. [CrossRef] [PubMed] 
33. Theoklitou, D.; Kabitsis, N.; Kabitsi, A. Physical and emotional abuse of primary school children by teachers. Child Abuse Negl. 2012, 36, 64-70. [CrossRef] [PubMed]

34. McEachern, A.G.; Aluede, O.; Kenny, M.C. Emotional abuse in the classroom: Implications and interventions for counsellors. J. Couns. Dev. 2008, 86, 3-10. [CrossRef]

35. Nesbit, W.C.; Philpot, D.F. Confronting subtle emotional abuse in classrooms. Guid. Couns. 2002, 17, 32-38.

36. Paul, J.L.; Smith, T.J. (Eds.) Stories Out of School: Memories and Reflections on Care and Cruelty in the Classroom; Ablex Publishing Corporation: New York, NY, USA, 2000.

37. Aroas, S. Teachers' psychological-emotional mistreatment of students. In Emotions in Teaching and School Management, a Collection of Articles; Optalka, Y., Ed.; MOFET Institute: Tel Aviv, Israel, 2018; pp. 120-158.

38. Whitted, K.S.; Dupper, D.R. Do teachers bully students? Findings from a survey of students in an alternative education setting. Educ. Urban Soc. 2008, 40, 329-341. [CrossRef]

39. Benbenishty, R.; Zeira, A.; Astor, R.A.; Khoury-Kassabri, M. Maltreatment of primary school students by educational staff in Israel. Child Abuse Negl. 2002, 26, 1291-1309. [CrossRef]

40. Goldstein, S.; Brook, R.B. Why study resilience? In Handbook of Resilience in Children; Goldstein, S., Brook, R.B., Eds.; Springer Business \& Media: New York, NY, USA, 2007.

41. Piekarska, A. School stress, teachers' abusive behaviors, and children's coping strategies. Child Abuse Negl. 2002, $24,1443-1449$. [CrossRef]

42. Katzman, B.; Dolev, N.; Koslowsky, M. Emotional intelligence as a mediator between teachers' emotional mistreatment and long-term emotional impact on students. Psychology 2021, 12, 304-319. [CrossRef]

43. Bar-On, R. The Emotional Quotient Inventory (EQ-i): Technical Manual; Multi-Health Systems: Toronto, ON, Canada, 2006.

44. Bronfenbrenner, U. Ecological models of human development. In Readings on the Development of Children, 2nd ed.; Gauvain, M., Cole, M., Eds.; Freeman: New York, NY, USA, 1994; pp. 37-43.

45. Ben-Eliyahu, A. Academic emotional learning: A critical component of self-regulated learning in the emotional learning cycle. Educ. Psychol. 2019, 54, 84-105. [CrossRef]

46. Zysberg, L.; Orenshtein, C.; Gimmon, E.; Robinson, R. Emotional intelligence, personality, stress, and burnout among educators. Int. J. Stress Manag. 2017, 24 (Suppl. S1), 122-136. [CrossRef]

47. Alvarado, A.; Spatariu, A.; Woodbury, C. Resilience \& emotional intelligence between first generation college students and non-first generation college students. Focus Coll. Univ. Sch. 2017, 11, 1-10.

48. Brackett, M.A.; Salovey, P. Measuring emotional intelligence with the Mayer-Salovery-Caruso Emotional Intelligence Test (MSCEIT). Psicothema 2006, 18, 34-41. [PubMed]

49. Miao, C.; Humphrey, R.H.; Qian, S. A meta-analysis of emotional intelligence and work attitudes. J. Occup. Organ. Psychol. 2017, 90, 177-202. [CrossRef]

50. Schneider, T.R.; Lyons, J.B.; Khazon, S. Emotional intelligence and resilience. Pers. Individ. Differ. 2013, 55, 909-914. [CrossRef]

51. Bibi, Z.; Karim, J. Workplace incivility and counterproductive work behavior: Moderating role of emotional intelligence. Pak. J. Psychol. Res. 2013, 28, 317-334.

52. Beltrán-Catalán, M.; Zych, I.; Ortega-Ruiz, R.; Llorent, V.J. Victimisation through bullying and cyberbullying: Emotional intelligence, severity of victimisation and technology use in different types of victims. Psicothema 2018, 30, 183-188. [CrossRef]

53. Kokkinos, C.M.; Kipritsi, E. The relationship between bullying, victimization, trait emotional intelligence, self-efficacy and empathy among preadolescents. Soc. Psychol. Educ. 2012, 15, 41-58. [CrossRef]

54. Pearson, C.M.; Porath, C.L. The Cost of Bad Behavior: How Incivility is Damaging Your Business and What to Do About It; Penguin Group: New York, NY, USA, 2009.

55. Thompson, H.L. The Stress Effect: Why Smart Leaders Make Dumb Decisions-And What to Do about It; John Wiley \& Sons: San Francisco, CA, USA, 2010.

56. Itzkovitch, Y.; Dolev, N. The relationships between emotional intelligence and perceptions of faculty incivility in higher education. Do men and women differ? Curr. Psychol. 2017, 36, 905-918. [CrossRef]

57. Connell, R. Teaching the boys: New research on masculinity, and gender strategies for schools. Teach. Coll. Rec. 1996, 98, 206-235.

58. Ellemers, N. Gender stereotypes. Annu. Rev. Psychol. 2018, 69, 275-298. [CrossRef]

59. Tiedemann, J. Gender-related beliefs of teachers in elementary school mathematics. Educ. Stud. Math. 2000, 41, 191-207. [CrossRef]

60. Leslie, S.J.; Cimpian, A.; Meyer, M.; Freeland, E. Expectations of brilliance underlie gender distributions across academic disciplines. Science 2015, 347, 262-265. [CrossRef] [PubMed]

61. Jones, G.M.; Wheatley, L. Gender differences in teacher-student interactions in science classrooms. J. Res. Sci. Teach. 1990, 27, 861-874. [CrossRef]

62. Kafetsios, K. Attachment and emotional intelligence abilities across the life course. Pers. Individ. Differ. 2004, 37, 129-145. [CrossRef]

63. Chen, J.K.; Whi, H.S. Student victimization by teachers in Taiwan: Prevalence and associations. Child Abuse Negl. 2011, 35, 382-390. [CrossRef] [PubMed] 
64. Kizıltepe, R.; Irmak, T.Y.; Eslek, D.; Hecker, T. Prevalence of violence by teachers and its association to students' emotional and behavioural problems and school performance: Findings from secondary school students and teachers in Turkey. Child Abuse Negl. 2020, 107, 104559. [CrossRef] [PubMed]

65. Khoury-Kassabri, M. Student victimization by educational staff in Israel. Child Abuse Negl. 2006, 30, 691-707. [CrossRef]

66. Romi, S.; Salkovsky, M.; Lewis, R. Reasons for aggressive classroom management and directions for change through teachers' professional development programmes. J. Educ. Teach. 2016, 42, 173-187. [CrossRef]

67. Bar-On, R.; Brown, J.M.; Kircaldy, B.D.; Thome, E.P. Emotional expression and implications for occupational stress: An application of the Emotional Quotient Inventory. Pers. Individ. Differ. 2000, 28, 1107-1118. [CrossRef]

68. Meshkat, M.; Nejati, R. Does emotional intelligence depend on gender? A study on undergraduate English majors of three Iranian universities. SAGE Open 2017, 7, 2158244017725796. [CrossRef]

69. Fischer, A.H.; Kret, M.E.; Broekens, J. Gender differences in emotion perception and self-reported emotional intelligence: A test of the emotion sensitivity hypothesis. PLoS ONE 2018, 13, e0190712. [CrossRef] [PubMed]

70. Ciarrochi, J.; Deane, F.P.; Anderson, S. Emotional intelligence moderates the relationship between stress and mental health. Pers. Individ. Diff. 2002, 32, 197-209. [CrossRef]

71. Hopkins, M.M.; Bilimoria, D. Social and emotional competencies predicting success for male and female executives. J. Manag. Dev. 2008, 2, 13-35. [CrossRef]

72. Marzuki, N.A.; Mustaffa, C.S.; Saad, Z.M.; Muda, S.; Abdullah, S.; Din, W.B.C. Emotional intelligence and demographic differences among students in public universities. Res. J. Organ. Psychol. Educ. Stud. 2012, 1, 93-99.

73. Myint, A.A.; Aung, A.A. The relationship between emotional intelligence and job performance of Myanmar school teachers. AsTEN J. Teach. Educ. 2016, 1, 1-16.

74. Craig, A.; Tran, Y.; Hermens, G.; Williams, L.M.; Kemp, A.; Morris, C.; Gordon, E. Psychological and neural correlates of emotional intelligence in a large sample of adult males and females. Pers. Individ. Differ. 2009, 46, 111-115. [CrossRef]

75. Naghavi, F.; Redzuan, M. The relationship between gender and emotional intelligence. World Appl. Sci. J. 2011, 15, 555-561.

76. Arteche, A.; Chamorro-Premuzic, T.; Furnham, A.; Crump, J. The relationship of trait EI with personality, IQ and sex in a UK sample of employees. Int. J. Select. Assess. 2008, 16, 421-426. [CrossRef]

77. Fernández-Berrocal, P.; Cabello, R.; Castillo, R.; Extremera, N. Gender differences in emotional intelligence: The mediating effect of age. Behav. Psychol. 2012, 20, 77-89.

78. Dhaundiyal, D.; Chakravarty, R.N.; Joshi, A. Hofstede and Hobbitses: Generational evolution of power distance and masculinity in UK in popular literature. In Proceedings of the IndiaHCI'20: 11th Indian Conference on Human-Computer Interaction, Online, India, 5-8 November 2020; pp. 1-11.

79. Hair, J.F.; Hult, G.T.M.; Ringle, C.M.; Sarstedt, M. A Primer on Partial Least Squares Structural Equation Modeling (PLS-SEM); Sage: Thousand Oaks, CA, USA, 2016.

80. Van de Vijver, F.; Hambleton, R.K. Translating tests. Eur. Psychol. 1996, 1, 89-99. [CrossRef]

81. Wong, C.S.; Law, K.S. The effects of leader and follower emotional intelligence on performance and attitude: An exploratory study. Leadersh. Q. 2002, 13, 243-274. [CrossRef]

82. Liebenberg, L.; Ungar, M.; LeBlanc, J.C. The CYRM-12: A brief measure of resilience. Can. J. Public Health 2013, 104, e131-e135. [CrossRef]

83. Proudfoot, D.; Kay, A.C.; Koval, C.Z. A gender bias in the attribution of creativity: Archival and experimental evidence for the perceived association between masculinity and creative thinking. Psychol. Sci. 2015, 26, 1751-1761. [CrossRef] [PubMed]

84. McGarty, C.; Smithson, M. Independence and nonindependence: A simple method for comparing groups using multiple measures and the binomial test. Eur. J. Soc. Psychol. 2005, 35, 171-180. [CrossRef]

85. Stein, S.J.; Book, H.E. The EQ Edge: Emotional Intelligence and Your Success; John Wiley\&Sons: Hoboken, NJ, USA, 2011.

86. Smyth, I.; Sweetman, C. Introduction: Gender and Resilience. Gend. Dev. 2015, 25, 405-414. [CrossRef]

87. Fida, A.; Ghaffar, A.; Zaman, A.; Sati, A. Gender comparison of emotional intelligence of university students. J. Educ. Educ. Dev. 2018, 5, 172-188. [CrossRef]

88. Itzkovich, Y. Why do leaders behave uncivil: A new perspective on workplace mistreatment and power. Wirtschaftspsychologie 2021, in press.

89. Itzkovich, Y.; Dolev, N. Cultivating a safer climate in the public sector: Mistreatment intervention using the four pillars of education. Societies 2021, 11, 48. [CrossRef]

90. Itzkovich, Y.; Barhon, E.; Lev-Wizel, R. Health and risk behaviours of bystanders: An integrative theoretical model of bystanders reactions to mistreatment. Int. J. Environ. Res. Public Health 2021, 18, 5552. [CrossRef] [PubMed]

91. Niven, K.; Ng, K.; Hoel, H. The bystanders of workplace bullying. In Bullying and Harassment in the Workplace: Theory, Research and Practice; Einarsen, S.V., Hoel, H., Zapf, D., Cooper, C.L., Eds.; CRC Press: Boca Raton, FL, USA, 2020; pp. $385-408$.

92. Ijadi-Maghsoodi, R.; Marlotte, L.; Garcia, E.; Aralis, H.; Lester, P.; Escudero, P.; Kataoka, S. Adapting and implementing a school-based resilience-building curriculum among low-income racial and ethnic minority students. Contemp. Sch. Psychol. 2017, 21, 223-239. [CrossRef] [PubMed]

93. Rodrigues, C.A.; Blumberg, H. Do feminine cultures really behave more feminine than masculine cultures? A comparison of 48 countries femininity-masculinity ranking to their UN human development rankings. Int. J. Cross Cult. Manag. 2000, 7, 25-34. [CrossRef] 